\title{
Osimertinib in Patients with T790M-Positive Advanced Non-small Cell Lung Cancer: Korean Subgroup Analysis from Phase II Studies
}

\section{Myung-Ju Ahn, MD' \\ Ji-Youn Han, MD, PhD² \\ Dong-Wan Kim, MD, PhD ${ }^{3}$ \\ Byoung Chul Cho, MD, $\mathrm{PhD}^{4}$ \\ Jin-Hyoung Kang, MD, PhD 5 \\ Sang-We Kim, MD, PhD ${ }^{6}$ \\ James Chih-Hsin Yang, MD, $\mathrm{PhD}^{7}$ \\ Tetsuya Mitsudomi, MD, $\mathrm{PhD}^{8}$ \\ Jong Seok Lee, MD, PhD ${ }^{9}$}

${ }^{1}$ Division of Hematology-Oncology,

Department of Medicine, Samsung Medical

Center, Sungkyunkwan University School of

Medicine, Seoul, ${ }^{2}$ Center for Lung Cancer,

National Cancer Center, Goyang,

${ }^{3}$ Department of Internal Medicine,

Seoul National University College of

Medicine, Seoul, ${ }^{4}$ Division of Medical

Oncology, Department of Internal Medicine,

Yonsei Cancer Center, Yonsei University

College of Medicine, Seoul, ${ }^{5}$ Division of

Medical Oncology, Department of Internal

Medicine, Seoul St. Mary's Hospital, College

of Medicine, The Catholic University of Korea,

Seoul, ${ }^{6}$ Department of Oncology,

Asan Medical Center, University of Ulsan

College of Medicine, Seoul, Korea,

${ }^{7}$ National Taiwan University and National

Taiwan University Hospital, Taipei, Taiwan,

${ }^{8}$ Kindai University Faculty of Medicine,

Osaka-Sayama, Japan, ${ }^{9}$ Division of

Hematology and Medical Oncology,

Department of Internal Medicine,

Seoul National University Bundang Hospital,

Seongnam, Korea

Correspondence: Jong Seok Lee, MD, PhD

Division of Hematology and Medical Oncology,

Department of Internal Medicine,

Seoul National University Bundang Hospital,

Seoul National University College of Medicine,

82 Gumi-ro 173beon-gil, Bundang-gu,

Seongnam 13620 , Korea

Tel: 82-31-787-7003

Fax: 82-31-787-4052

E-mail: jslee0918@gmail.com

Received April 12, 2019

Accepted July 16, 2019

Published Online July 23, 2019

\section{Purpose}

Osimertinib is a third-generation, irreversible, oral epidermal growth factor receptor (EGFR) tyrosine kinase inhibitor (TKI) that potently and selectively inhibits both EGFR sensitizing mutation and EGFR T790M and has demonstrated efficacy in non-small cell lung cancer (NSCLC) central nervous system (CNS) metastases. We present results of a subgroup analysis of Korean patients from the pooled data of two global phase II trials: AURA extension (NCT01802632) and AURA2 (NCT02094261).

\section{Materials and Methods}

Enrolled patients had EGFR T790M-positive NSCLC and disease progression during or after EGFR-TKI therapy. Patients received osimertinib $80 \mathrm{mg}$ orally once daily until disease progression. The primary endpoint was objective response rate (ORR).

\section{Results}

In total, 66 Korean patients received osimertinib treatment with a median treatment duration of 19 months. In the evaluable-for-response population ( $n=62)$, ORR was $74 \%(95 \%$ confidence interval [CI], 61.5 to 84.5 ) and median duration of response was 9.8 months $(95 \% \mathrm{Cl}, 7.1$ to 16.8$)$. In the full analysis set $(n=66)$, median progression-free survival was 10.9 months ( $95 \% \mathrm{Cl}, 8.3$ to 15.0; data cutoff November 1, 2016), and median overall survival was 29.2 months ( $95 \% \mathrm{Cl}, 24.8$ to 35.7; data cutoff May 1, 2018). Eight patients with CNS metastases were evaluable for response, none of whom showed CNS progression. The most common adverse events were rash (53\%), cough (33\%), paronychia, diarrhea, and decreased appetite (each 32\%).

\section{Conclusion}

Efficacy and safety profiles of osimertinib in this subgroup are consistent with the global phase II pooled population, which supports osimertinib as a recommended treatment for Korean patients with T790M positive NSCLC.

\section{Key words}

Non-small-cell lung carcinoma, Tyrosine kinase inhibitor, Epidermal growth factor receptor, South Korea, Clinical trial, Phase II 


\section{Introduction}

Epidermal growth factor receptor (EGFR) tyrosine kinase inhibitors (TKIs) are the standard first-line treatment for patients with advanced non-small cell lung cancer (NSCLC) harboring an EGFR-TKI sensitizing mutation (EGFRm) [1-3]. The majority of patients who initially respond to EGFR-TKIs ultimately develop resistance [4-6]; for patients who develop resistance to a first- or second-generation EGFR-TKI, T790M is observed in approximately 50\% [7].

Osimertinib is a third-generation, irreversible, oral EGFRTKI that potently and selectively inhibits both EGFRm and EGFR T790M and has demonstrated efficacy in NSCLC central nervous system (CNS) metastases [8-12]. In a pooled analysis of two phase II studies, AURA extension (NCT01802632) and AURA2 (NCT02094261) [13-15], in patients with T790M positive advanced NSCLC and disease progression after prior EGFR-TKI therapy, high objective response rates (ORR; 66\%; 95\% confidence interval [CI], 61 to 70), and prolonged median progression-free survival (PFS; 9.9 months; 95\% CI, 9.5 to 12.3 ) were observed with osimertinib. The pooled phase II results were consistent with that observed in the AURA3 phase III trial (NCT02151981), in which osimertinib therapy was compared with platinum-based chemotherapy plus pemetrexed in patients with T790M-positive NSCLC following disease progression on first-line EGFRTKI. Median PFS was consistently longer with osimertinib: 10.1 versus 4.4 months (hazard ratio, $0.30 ; 95 \% \mathrm{CI}, 0.23$ to $0.41 ; \mathrm{p}<0.001$ ) [12]. Osimertinib also provided a higher and more durable CNS response rate, and longer CNS PFS compared with platinum-pemetrexed [16].

Here we present results from a post-hoc analysis of the Korean subgroup from the two global phase II studies, AURA extension and AURA2, which investigated the efficacy and safety of osimertinib in patients with pre-treated EGFRm advanced NSCLC with centrally determined T790M positive status. This subgroup was selected because Korean patients made up a significant proportion of the global population in these studies and, as in the overall East Asian population, the rate of EGFR mutation among patients with NSCLC is much higher in the Korean than in the Caucasian population $(30 \%$ $34 \%$ vs. $10 \%-17 \%$ ) [17-20].

\section{Materials and Methods}

\section{Study design}

AURA extension and AURA2 were phase II, single-arm, open-label, multicenter studies. Full methodology for each study has been previously reported [13-15].

The study protocols were designed by the sponsor (AstraZeneca) and the study investigators.

\section{Eligibility criteria}

Both studies enrolled patients who were 18 years or older with a histologically or cytologically confirmed diagnosis of NSCLC and T790M positive status with radiological disease progression on their most recent treatment regimen. Eligible patients had a World Health Organization (WHO) performance status of 0 or 1 and disease progression following previous EGFR-TKI therapy, either with or without additional anti-cancer regimens. Patients with spinal cord compression or brain metastases could be included if the disease was stable, asymptomatic and did not require steroids for 4 weeks prior to the first dose of study drug.

\section{Study treatment}

All patients received osimertinib $80 \mathrm{mg}$ orally once daily until disease progression (as defined by Response Evaluation Criteria in Solid Tumors [RECIST] ver. 1.1) or until a discontinuation criterion was met. Patients could continue to receive osimertinib after disease progression provided they showed clinical benefit (investigator assessed). If study treatment was discontinued for any reason other than disease progression, RECIST ver. 1.1 assessments continued every 6 weeks until disease progression, regardless of further treatment regimens.

\section{Study endpoints}

The primary endpoint of AURA extension and AURA2 was ORR by blinded independent central review (BICR). Additional efficacy endpoints included duration of response (DoR), PFS, and tumor shrinkage. Safety and tolerability, and overall survival (OS), were evaluated in all patients receiving at least one dose of osimertinib (full analysis set). Investigators recorded and graded adverse events (AEs) according to the National Cancer Institute's Common Terminology Criteria for Adverse Events ver. 4.0. 


\section{Study assessments}

Tumor response was evaluated by BICR. Computed tomography or magnetic resonance imaging scans were taken at baseline, then every 6 weeks from the first dose of osimertinib until disease progression. RECIST ver. 1.1 was used to assess ORR, PFS, DoR, disease control rate and tumor shrinkage, and a sensitivity analysis was performed using investigator assessment of RECIST ver. 1.1.

\section{Statistical analysis}

The Korean subgroup comprised all patients from each study who were enrolled at Korean sites and treated with osimertinib. The full analysis set (FAS) was defined as all patients enrolled who received at least one dose of study treatment. The evaluable-for-response (EFR) analysis set was defined as all patients who received at least one dose of study treatment and had measurable disease at baseline according to BICR. Response endpoints including ORR, DoR and change in tumor size were analyzed in the EFR set, with a data cutoff of November 1, 2016. PFS, defined as the time from date of first dose until the date of objective disease progression or death (regardless of whether the patient withdrew from study treatment or received another anti-cancer therapy prior to progression), was analyzed in the FAS at data cutoff November 1, 2016. CNS methodology has been previously published [21]. Briefly, CNS efficacy was assessed in an evaluable-for-CNS-response analysis set, which included patients with at least one measurable CNS lesion on baseline brain scan (RECIST ver. 1.1) by BICR (assessed by neuroradiologists), with an earlier data cutoff of November 1,2015 . OS data were immature at the time of data cutoff for the primary efficacy analyses (November 1, 2016); therefore, OS was analyzed in the FAS at a later cutoff date of May 1, 2018. Safety and tolerability analyses are also presented for the later cutoff date of May 1, 2018, to maximize available safety data for this patient population.

Statistical analyses were performed by PPD (Wilmington, $\mathrm{NC}$ ). All calculations were performed with SAS software ver. 9.2 (SAS Institute Inc., Cary, NC), unless otherwise stated.

\section{Ethical statement}

All participating sites in both studies obtained approval from their independent institutional review boards or independent ethics committees. The AURA extension and AURA2 studies were performed in accordance with the ethical principles that have their origin in the Declaration of Helsinki and that are consistent with International Conference on Harmonisation/Good Clinical Practice, applicable regulatory requirements, and AstraZeneca's policy on bioethics. All patients provided written informed consent prior to their participation in the studies.

\section{Results}

\section{Patients}

Of those patients included in the AURA2 and AURA extension studies, 66 of 411 (16\%) were Korean. These patients were enrolled from seven sites and received osimertinib across the two phase II trials; 41 of 201 patients in the AURA extension study and 25 of 210 patients in the AURA2 study. Patient demographics and baseline characteristics are summarized in Table 1. The majority of patients were female $(70 \%)$, never smokers $(73 \%)$, with a median age of 60.5 years. The most recent therapy for $70 \%$ of patients was an EGFRTKI and 56\% had previously received platinum chemotherapy. $94 \%$ of patients had metastatic disease and $30 \%$ had CNS metastases.

\section{Efficacy}

At data cutoff for the primary analysis (November 1, 2016), the median duration of exposure to osimertinib was 19.3 months (range, 0.5 to 28.1 months; mean, 17.4 months); 19 patients $(29 \%)$ were still receiving treatment.

Four patients' results were not considered evaluable: one had an unconfirmed partial response, two had a complete response but had no measurable disease and one had no evaluable follow-up assessments. In the EFR Korean population ( $\mathrm{n}=62)$, the ORR was $74 \%$ (46/62; 95\% CI, 61.5 to 84.5). In the EFR, 2 of 62 patients ( $3 \%$ ) had a best objective response of complete response, 44 of 62 patients $(71 \%)$ had a partial response and $13(21 \%)$ had stable disease $\geq 6$ weeks (Table 2). Disease control rate in the EFR was $95 \%$ (59/62; 95\% CI, 86.5 to 99.0 ). The mean best percentage change in target lesion size was $-52 \%$ (Fig. 1). Among patients with an objective response $(n=46)$, median time to response from first dose was 5.6 weeks and median DoR was 9.8 months (95\% CI, 7.1 to 16.8) (Fig. 2A).

At the primary data cutoff (November 1, 2016), the median duration of follow-up was 9.6 months. In total, 45 of 66 patients $(68 \%)$ had reported a progression event. Among the 21 patients with no disease progression at data cutoff according to investigator assessment, 13 patients were progression-free, four patients withdrew consent, and four patients had RECIST progression or death censored (RECIST-defined disease progression or death occurred 19 weeks after the last evaluable RESIST assessment). None of these patients were lost to 
Table 1. Baseline demographics and disease characteristics, full analysis set

\begin{tabular}{|c|c|}
\hline Characteristic & No. $(\%)(n=66)$ \\
\hline Age, median (range, yr) & $61(40-78)$ \\
\hline \multicolumn{2}{|l|}{ Sex } \\
\hline Male & $20(30.3)$ \\
\hline Female & $46(69.7)$ \\
\hline \multicolumn{2}{|l|}{ Race } \\
\hline Asian & $66(100)$ \\
\hline \multicolumn{2}{|l|}{ Smoking status } \\
\hline Never & $48(72.7)$ \\
\hline Current & $1(1.5)$ \\
\hline Former & $17(25.8)$ \\
\hline \multicolumn{2}{|l|}{ WHO performance status } \\
\hline 0 & $20(30.3)$ \\
\hline 1 & $46(69.7)$ \\
\hline \multicolumn{2}{|l|}{ Overall disease classification } \\
\hline Metastatic $^{\text {a) }}$ & $62(93.9)$ \\
\hline Locally advanced ${ }^{\mathrm{b})}$ & $4(6.1)$ \\
\hline \multicolumn{2}{|l|}{ Histology type } \\
\hline Adenocarcinoma (NOS) & $65(98.5)$ \\
\hline Adenocarcinoma: acinar & $1(1.5)$ \\
\hline \multicolumn{2}{|l|}{ EGFR mutationsc) } \\
\hline $\mathrm{T} 790 \mathrm{M}$ & $66(100)$ \\
\hline Exon 19 deletion & $45(68.2)$ \\
\hline L858R & $19(28.8)$ \\
\hline T790M only & $2(3.0)$ \\
\hline CNS metastases $^{\mathrm{d})}$ & $20(30.3)$ \\
\hline Visceral metastases $^{\text {d) }}$ & $34(51.5)$ \\
\hline \multicolumn{2}{|l|}{ Prior EGFR-TKI } \\
\hline Gefitinib & $50(75.8)$ \\
\hline Erlotinib & $17(25.8)$ \\
\hline Afatinib & $6(9.1)$ \\
\hline Dacomitinib & $3(4.5)$ \\
\hline Other & $3(4.5)$ \\
\hline Prior platinum chemotherapy & $37(56.1)$ \\
\hline
\end{tabular}

(Continued)

follow up or discontinued treatment. The median PFS in the FAS was 10.9 months (95\% CI, 8.3 to 15.0 ), and $80 \%$ of patients were alive and progression-free at 6 months, $46 \%$ at 12 months and $20 \%$ at 24 months (Fig. 2B).

In the FAS, 20 patients had CNS metastases at study entry, of whom eight were evaluable for CNS response after receiving osimertinib once daily. These patients' demographics were closely aligned with the overall subset population: median age of 62 years, $75 \%$ female and all were Asian. The median lesion size in these evaluable patients was $20 \mathrm{~mm}$ (range, 10 to $41 \mathrm{~mm}$ ), with a total of four $(50 \%)$ having received any previous local treatment for brain metastases (exclu-
Table 1. Continued

\begin{tabular}{lc} 
Characteristic & No. $(\%)(\mathrm{n}=66)$ \\
First-line & $25(37.9)$ \\
Second-line & $6(9.1)$ \\
Third-line & $5(7.6)$ \\
$>$ Third-line & $1(1.5)$ \\
Not applicable & $2(3.0)$ \\
\hline
\end{tabular}

Values are presented as number (\%) unless otherwise indicated. WHO, World Health Organization; NOS, not otherwise specified; EGFR, epidermal growth factor receptor; CNS, central nervous system; TKI, tyrosine kinase inhibitor. ${ }^{a}$ Metastatic disease: patient has any metastatic site of disease, ${ }^{\text {b)} L o c a l l y ~ a d v a n c e d: ~ p a t i e n t ~ h a s ~ o n l y ~ l o c a l l y ~}$ advanced sites of disease, ${ }^{c} E G F R$ mutation identified by the Cobas EGFR central test (by biopsy taken after confirmation of disease progression on the most recent treatment regimen), ${ }^{\mathrm{d}} \mathrm{CNS}$ and visceral metastases are determined programmatically from baseline data, ${ }^{\mathrm{e}}$ Patients who received disease-related prior therapy will be counted at least once under the category of any and at least once under the relevant number of regimens.

ding whole brain radiotherapy), assessed by medical review. Of the patients evaluable for response, three (38\%) showed confirmed partial CNS response while the remaining five patients $(63 \%)$ showed stable CNS disease of $\geq 6$ weeks. None of the eight patients showed CNS disease progression

Table 2. Best objective response in the evaluable-for-response analysis set

\begin{tabular}{|c|c|}
\hline Response & Total $(n=62)$ \\
\hline Complete response $^{a)}$ & $2(3.2)$ \\
\hline Partial response $e^{a)}$ & $44(71.0)$ \\
\hline Stable disease $\geq 6$ weeks ${ }^{\text {b) }}$ & $13(21.0)$ \\
\hline Progressive disease & $2(3.2)$ \\
\hline Not evaluable & $1(1.6)$ \\
\hline Disease control rate & $59(95.2)$ \\
\hline $95 \% \mathrm{CI}$ & $86.5-99.0$ \\
\hline Objective response rate & $46(74.2)$ \\
\hline $95 \% \mathrm{CI}$ & $61.5-84.5$ \\
\hline
\end{tabular}

Values are presented as number (\%) unless otherwise indicated. Data cutoff November 1, 2016. The CIs are calculated using Clopper-Pearson exact method for binomial proportions. CI, confidence interval; RECIST, Response Evaluation Criteria In Solid Tumors. ${ }^{\text {a) }}$ Responses required confirmation after 4 weeks, b) Stable disease $\geq 6$ weeks includes RECIST visit window ( \pm 7 days). 


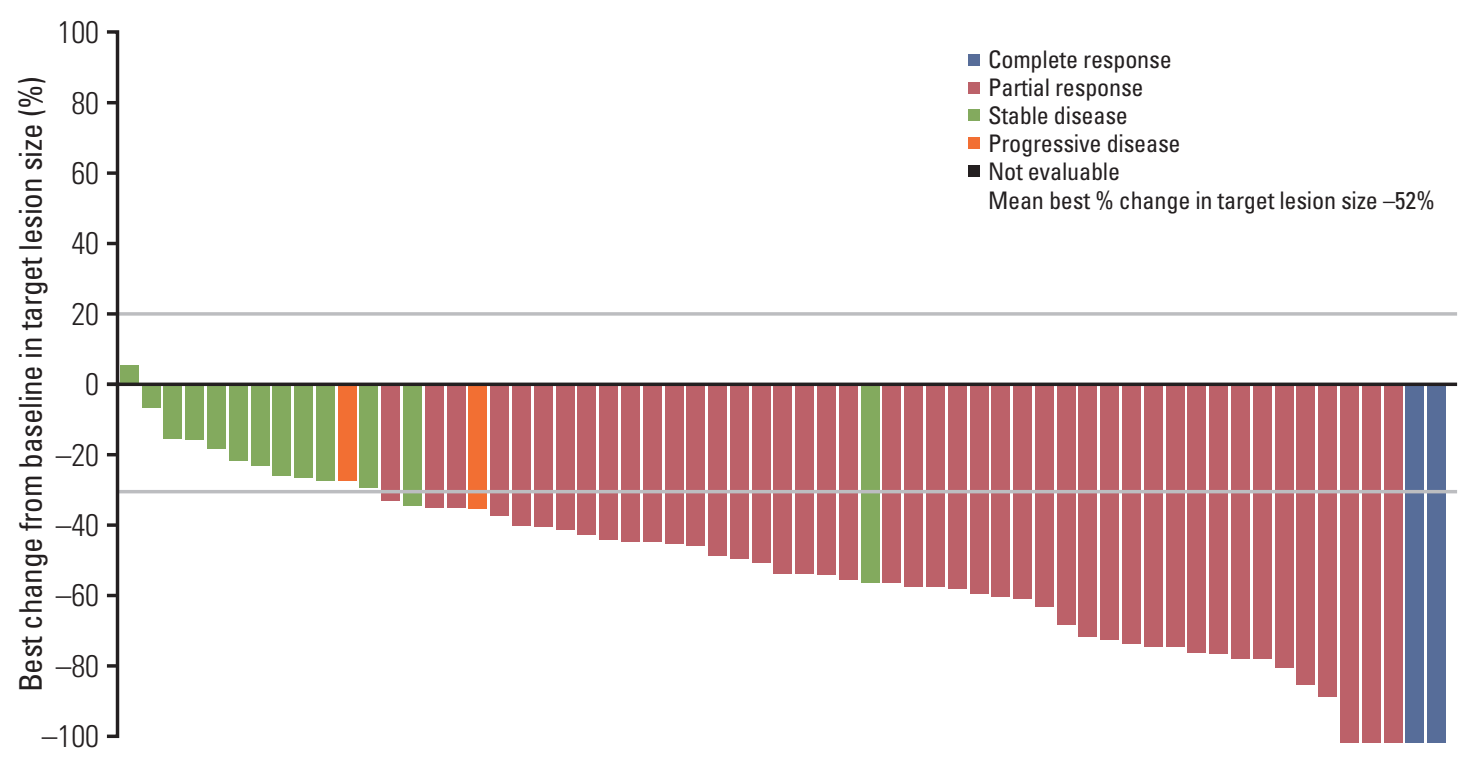

Fig. 1. Waterfall plot of target lesion size, best percentage change from baseline by blinded independent central review (evaluable-for-response set). Best percentage change in target lesion size is the maximum reduction from baseline or the minimum increase from baseline in the absence of a reduction. Data cutoff November 1, 2016.

A
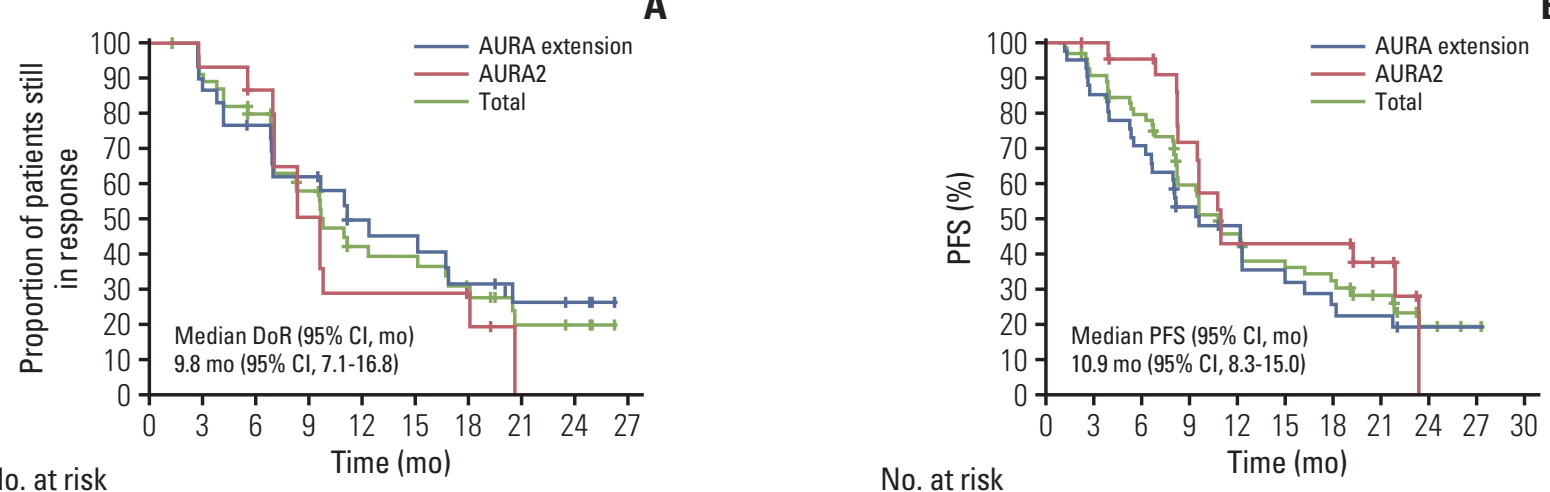

No. at risk

No. at risk

Time (mo)

$\begin{array}{rrrrrrrrrr}\text { AURA extension } & 30 & 27 & 22 & 16 & 11 & 10 & 7 & 5 & 4 \\ \text { AURA2 } & 16 & 14 & 12 & 7 & 4 & 4 & 3 & 0 & 0 \\ \text { Total } & 46 & 41 & 34 & 23 & 15 & 14 & 10 & 5 & 4\end{array}$

$\begin{array}{rrrrrrrrrrr}\text { AURA extension } & 41 & 35 & 29 & 20 & 16 & 11 & 8 & 7 & 5 & 1 \\ \text { AURA2 } & 25 & 23 & 21 & 15 & 9 & 9 & 9 & 5 & 0 & 0 \\ \text { Total } & 66 & 58 & 50 & 35 & 25 & 20 & 17 & 12 & 5 & 1\end{array}$

Fig. 2. Kaplan-Meier analysis of osimertinib $80 \mathrm{mg}$ once daily treatment in Korean patients from AURA extension and AURA 2 studies. (A) Duration of response (DoR) by blinded independent central review (evaluable-for-response set) by study and total. (B) Progression-free survival (PFS) by blinded independent central review (full analysis set) by study and total. Tick marks indicate censored observations. Data cutoff November 1, 2016. CI, confidence interval.

at the time of data cutoff for the CNS efficacy analysis (November 1, 2015); median PFS for these eight patients was 4 months (95\% CI, 2.7 to not calculable).

At the later data cutoff of May 1, 2018, the median duration of exposure to osimertinib was 19.3 months (range, 0.5 to 46.0 months; mean, 20.3 months); 7 patients (11\%) remained on treatment. The median duration of follow-up was 27.9 months. A total of 44 patients $(67 \%)$ had died. Median OS was 29.2 months (95\% CI, 24.8 to $35.7 ;$ FAS). OS at 12, 24, and 36 months was $83 \%, 64 \%$, and $37 \%$, respectively. 
Table 3. Summary of adverse events (full analysis set)

\begin{tabular}{lc} 
AE category & No. $(\%)(\mathbf{n}=66)$ \\
\hline All causality & \\
\hline Any AE & $66(100)$ \\
Any AE grade $\geq 3$ & $23(34.8)$ \\
Any AE leading to death & $1(1.5)$ \\
Any AE leading to dose interruption & $19(28.8)$ \\
Any AE leading to dose reduction & $1(1.5)$ \\
Any AE leading to discontinuation & $4(6.1)$ \\
Any serious AE & $19(28.8)$ \\
Possibly causally related ${ }^{\text {a) }}$ & \\
Any AE & $58(87.9)$ \\
Any AE grade $\geq 3$ & $6(9.1)$ \\
Any AE leading to discontinuation & $2(3.0)$ \\
Any serious AE & 0 \\
\hline Any AE leading to death & 0 \\
\hline
\end{tabular}

Values are presented as number $(\%)$ unless otherwise indicated. Data cutoff May 1, 2018. Includes adverse events with an onset date on or after the date of first dose and up to and including 28 days following the date of last dose of study medication. $\mathrm{AE}$, adverse event. ${ }^{\mathrm{a}}$ Causally related as assessed by the investigator.

\section{Safety}

At least one AE was reported in all patients $(100 \%, 66 / 66)$ (Table 3). Fifty-eight patients (88\%) reported AEs that were possibly causally related to osimertinib (assessed by the investigator). AEs grade $\geq 3$ were reported in 23 of 66 patients (35\%), Grade $\geq 3$ AEs possibly casually-related to osimertinib were reported in six patients $(9 \%)$. There was one report of a fatal AE (cerebral infarction); however, this was not considered to be causally related to osimertinib.

The most commonly reported AEs were rash (grouped term including rashes and acnes; $53 \%$ of patients, $0 \%$ grade $\geq 3)$, pruritus ( $32 \% ; 0 \%$ grade $\geq 3)$, cough $(33 \% ; 0 \%$ grade $\geq 3)$, paronychia (grouped term including general nail/nail bed conditions; $32 \% ; 0 \%$ grade $\geq 3)$, diarrhea $(32 \% ; 2 \%$ grade $\geq 3)$ and decreased appetite ( $32 \% ; 0 \%$ grade $\geq 3$ ) (Table 4$)$. One patient developed interstitial lung disease and one patient developed pneumonitis, both of which were grade 1 in severity and were considered to be possibly causally related to osimertinib by the investigator. Both events resolved on discontinuation of osimertinib. No patients had AEs of QT prolongation recorded.

\section{Discussion}

In this subgroup analysis of Korean patients from two global phase II studies in pre-treated patients with T790M positive advanced NSCLC (AURA extension and AURA2), osimertinib therapy resulted in an ORR of $74 \%$ with a median DoR of 9.8 months and a median PFS of 10.9 months (as of data cutoff November 1, 2016). Longer-term follow-up (data cutoff May 1, 2018; median follow-up, 27.9 months) showed a median OS of 29.2 months. The safety profile of osimertinib in Korean patients was consistent with the overall safety profile of osimertinib [12-14], with a low rate of grade $\geq 3$ possibly causally related AEs.

In the global phase II pooled analysis from AURA extension and AURA2 studies, the ORR was $66 \%$, with a median DoR of 12.3 months and median PFS of 9.9 months, and median OS 26.8 months on prolonged follow-up [15]. In the phase III AURA3 trial, ORR and median DoR by investigator assessment with osimertinib were $71 \%$ and 9.7 months respectively, while median PFS by BICR and investigator assessment was 11.0 and 10.1 months, respectively, showing concordance between the two [12]. The efficacy results of the current analysis in a Korean population are consistent with the global population, with ORR slightly higher. This confirms that the efficacy of osimertinib is not different in patients of Korean ethnicity, and supports the recommendation for use of osimertinib in Korean patients with T790M positive advanced NSCLC following disease progression after EGFRTKI therapy $[2,17]$.

The AEs reported in this Korean subgroup were consistent with the global phase II and III studies [12-14]. Rash, diarrhea, paronychia, and dry skin have consistently been reported as the most common AEs with osimertinib treatment. For each of these AEs, the majority of cases reported were grade 1 or 2 in severity. Potential differences in reported AEs in the Korean subgroup compared with the global pooled population [15] were the overall frequencies of diarrhea (Korean subgroup $32 \%$ vs. global population $49 \%$ ), dry skin (15\% vs. $36 \%)$, pruritus ( $32 \%$ vs. $18 \%$ ), platelet count decreased ( $27 \%$ vs. $14 \%)$, and anemia (27\% vs. $18 \%)$. However, comparisons should be viewed with caution because of the small number of patients in this Korean subgroup.

Brain metastases have been reported to occur in 25\%-40\% of patients with EGFR mutation-positive NSCLC [22]. Phase II and III studies with osimertinib report CNS activity in patients with T790M positive NSCLC $[13,16,21]$. The CNS activity in this Korean subgroup appears to be consistent with previous reports, supporting the use of osimertinib as treatment of choice for patients with CNS metastases and EGFRm NSCLC.

A limitation of this analysis is the small number of Korean 
Table 4. All causality adverse events occurring in $\geq 10 \%$ of patients (full analysis set)

\begin{tabular}{|c|c|c|c|c|c|}
\hline Adverse event & Total & Grade 1 & Grade 2 & Grade 3 & Grade 4 \\
\hline Rasha) $^{\text {a) }}$ & $35(53.0)$ & $34(51.5)$ & $1(1.5)$ & 0 & 0 \\
\hline Cough & $22(33.3)$ & $18(27.3)$ & $4(6.1)$ & 0 & 0 \\
\hline Paronychiaa) & $21(31.8)$ & $19(28.8)$ & $2(3.0)$ & 0 & 0 \\
\hline Diarrhea & $21(31.8)$ & $14(21.2)$ & $6(9.1)$ & $1(1.5)$ & 0 \\
\hline Pruritus & $21(31.8)$ & $19(28.8)$ & $2(3.0)$ & 0 & 0 \\
\hline Decreased appetite & $21(31.8)$ & $17(25.8)$ & $4(6.1)$ & 0 & 0 \\
\hline Platelet count decreased & $18(27.3)$ & $14(21.2)$ & $3(4.5)$ & $1(1.5)$ & 0 \\
\hline Anemia & $18(27.3)$ & $7(10.6)$ & $7(10.6)$ & $4(6.1)$ & 0 \\
\hline Constipation & $16(24.2)$ & $13(19.7)$ & $3(4.5)$ & 0 & 0 \\
\hline Nausea & $16(24.2)$ & $10(15.2)$ & $5(7.6)$ & $1(1.5)$ & 0 \\
\hline Dyspepsia & $14(21.2)$ & $9(13.6)$ & $5(7.6)$ & 0 & 0 \\
\hline Stomatitis & $13(19.7)$ & $9(13.6)$ & $4(6.1)$ & 0 & 0 \\
\hline Neutrophil count decreased & $12(18.2)$ & $9(13.6)$ & $3(4.5)$ & 0 & 0 \\
\hline Vomiting & $12(18.2)$ & $10(15.2)$ & $1(1.5)$ & $1(1.5)$ & 0 \\
\hline Dermatitis acneiform & $12(18.2)$ & $12(18.2)$ & 0 & 0 & 0 \\
\hline Dry skina) & $10(15.2)$ & $10(15.2)$ & 0 & 0 & 0 \\
\hline White blood cell count decreased & $9(13.6)$ & $3(4.5)$ & $6(9.1)$ & 0 & 0 \\
\hline Back pain & $9(13.6)$ & $5(7.6)$ & $4(6.1)$ & 0 & 0 \\
\hline Musculoskeletal pain & $9(13.6)$ & $2(3.0)$ & $7(10.6)$ & 0 & 0 \\
\hline Insomnia & $8(12.1)$ & $6(9.1)$ & $2(3.0)$ & 0 & 0 \\
\hline Productive cough & $8(12.1)$ & $5(7.6)$ & $3(4.5)$ & 0 & 0 \\
\hline Musculoskeletal chest pain & $7(10.6)$ & $6(9.1)$ & $1(1.5)$ & 0 & 0 \\
\hline Upper respiratory tract infection & $7(10.6)$ & $3(4.5)$ & $4(6.1)$ & 0 & 0 \\
\hline Fatigue & $7(10.6)$ & $6(9.1)$ & $1(1.5)$ & 0 & 0 \\
\hline ALT increased & $7(10.6)$ & $6(9.1)$ & $1(1.5)$ & 0 & 0 \\
\hline
\end{tabular}

Values are presented as number (\%) unless otherwise indicated. Data cutoff May 1, 2018. Includes adverse events with an onset date on or after the date of first dose and up to and including 28 days following the date of last dose of study medication. ALT, alanine aminotransferase. ${ }^{a}$ Grouped terms adverse event.

patients that were enrolled and received osimertinib. However, the efficacy, safety, and tolerability profiles of osimertinib in this Korean subgroup were consistent with the global phase II studies, which is indicative of the broadly beneficial effects of osimertinib in the wider Korean population.

In conclusion, osimertinib provides a high response rate and prolonged PFS and OS, with a low incidence of grade $\geq 3$ AEs in Korean patients with T790M-positive advanced NSCLC.

\section{Conflicts of Interest}

Dong-Wan Kim reports personal expenses from Novartis. Jin-Hyoung Kang reports research funding from AstraZeneca, during the conduct of the study; research funding from CKD, Ono Pharmaceutical, and Johnson \& Johnson; advisory board participation for AstraZeneca, Eli Lilly, Merck Sharp \& Dohme, and Genexin; honoraria from Roche, Novartis, Merck Sharp \& Dohme, Ono Pharmaceutical, and Bristol-Myers Squibb, outside the submitted work.
James Chih-Hsin Yang reports personal fees from Boehringer Ingelheim, Eli Lilly, Bayer, Roche/Genentech, Chugai, Astellas, Merck Sharp \& Dohme, Merck Serono, Pfizer, Novartis, Clovis Oncology, Celgene, Merrimack, Yuhan Pharmaceuticals, BristolMyers Squibb, Ono Pharmaceuticals, Daiichi Sankyo, Astrazeneca, and Hansoh Pharmaceuticals, outside the submitted work.

Tetsuya Mitsudomi reports personal fees from AstraZeneca, during the conduct of the study; grants and personal fees from Boehringer Ingelheim, grants and personal fees from Chugai, personal fees from Roche, personal fees from Pfizer, grants and personal fees from Merck Sharp \& Dohme, grants and personal fees from Ono Pharmaceutical, personal fees from Bristol-Myers Squibb, and grants and personal fees from Taiho, outside the submitted work.

The other authors report no conflicts of interest.

\section{Acknowledgments}

The authors would like to thank the patients and their families. The studies NCT01802632 and NCT02094261 were funded by Astra- 
Zeneca, Cambridge, UK, the manufacturer of osimertinib. The authors would like to acknowledge Bernadette Tynan, MSc, of iMed Comms, Macclesfield, UK, an Ashfield Company, part of UDG
Healthcare plc, for medical writing support that was funded by AstraZeneca, Cambridge, UK, in accordance with Good Publications Practice (GPP3) guidelines (http://www.ismpp.org/gpp3).

\section{References}

1. Tan DS, Yom SS, Tsao MS, Pass HI, Kelly K, Peled N, et al. The International Association for the Study of Lung Cancer Consensus Statement on optimizing management of EGFR mutation-positive non-small cell lung cancer: status in 2016. J Thorac Oncol. 2016;11:946-63.

2. Hanna N, Johnson D, Temin S, Baker S Jr, Brahmer J, Ellis PM, et al. Systemic therapy for stage IV non-small-cell lung cancer: American Society of Clinical Oncology Clinical Practice Guideline update. J Clin Oncol. 2017;35:3484-515.

3. Planchard D, Popat S, Kerr K, Novello S, Smit EF, Faivre-Finn $\mathrm{C}$, et al. Metastatic non-small cell lung cancer: ESMO Clinical Practice Guidelines for diagnosis, treatment and follow-up. Ann Oncol. 2018;29(Suppl 4):iv192-237.

4. Rosell R, Carcereny E, Gervais R, Vergnenegre A, Massuti B, Felip E, et al. Erlotinib versus standard chemotherapy as firstline treatment for European patients with advanced EGFR mutation-positive non-small-cell lung cancer (EURTAC): a multicentre, open-label, randomised phase 3 trial. Lancet Oncol. 2012;13:239-46.

5. Mok TS, Wu YL, Thongprasert S, Yang CH, Chu DT, Saijo N, et al. Gefitinib or carboplatin-paclitaxel in pulmonary adenocarcinoma. N Engl J Med. 2009;361:947-57.

6. Sequist LV, Yang JC, Yamamoto N, O'Byrne K, Hirsh V, Mok $\mathrm{T}$, et al. Phase III study of afatinib or cisplatin plus pemetrexed in patients with metastatic lung adenocarcinoma with EGFR mutations. J Clin Oncol. 2013;31:3327-34.

7. Wang ZF, Ren SX, Li W, Gao GH. Frequency of the acquired resistant mutation T790 $\mathrm{M}$ in non-small cell lung cancer patients with active exon 19Del and exon 21 L858R: a systematic review and meta-analysis. BMC Cancer. 2018;18:148.

8. Cross DA, Ashton SE, Ghiorghiu S, Eberlein C, Nebhan CA, Spitzler PJ, et al. AZD9291, an irreversible EGFR TKI, overcomes T790M-mediated resistance to EGFR inhibitors in lung cancer. Cancer Discov. 2014;4:1046-61.

9. Soria JC, Ohe Y, Vansteenkiste J, Reungwetwattana T, Chewaskulyong B, Lee KH, et al. Osimertinib in untreated EGFRmutated advanced non-small-cell lung cancer. N Engl J Med. 2018;378:113-25.

10. Wu YL, Ahn MJ, Garassino MC, Han JY, Katakami N, Kim HR, et al. CNS efficacy of osimertinib in patients with T790Mpositive advanced non-small-cell lung cancer: data from a randomized phase III trial (AURA3). J Clin Oncol. 2018;36: 2702-9.

11. Reungwetwattana T, Nakagawa K, Cho BC, Cobo M, Cho EK, Bertolini A, et al. CNS response to osimertinib versus standard epidermal growth factor receptor tyrosine kinase inhibitors in patients with untreated EGFR-mutated advanced non-small- cell lung cancer. J Clin Oncol. 2018;36:3290-7.

12. Mok TS, Wu YL, Ahn MJ, Garassino MC, Kim HR, Ramalingam SS, et al. Osimertinib or platinum-pemetrexed in EGFR T790M-positive lung cancer. N Engl J Med. 2017;376:629-40.

13. Yang JC, Ahn MJ, Kim DW, Ramalingam SS, Sequist LV, Su WC, et al. Osimertinib in pretreated T790M-positive advanced non-small-cell lung cancer: AURA study phase II extension component. J Clin Oncol. 2017;35:1288-96.

14. Goss G, Tsai CM, Shepherd FA, Bazhenova L, Lee JS, Chang GC, et al. Osimertinib for pretreated EGFR Thr790Met-positive advanced non-small-cell lung cancer (AURA2): a multicentre, open-label, single-arm, phase 2 study. Lancet Oncol. 2016;17:1643-52.

15. Ahn MJ, Tsai CM, Shepherd FA, Bazhenova L, Sequist LV, Hida T, et al. Osimertinib in patients with T790M mutationpositive, advanced non-small cell lung cancer: long-term follow-up from a pooled analysis of 2 phase 2 studies. Cancer. 2019;125:892-901.

16. Mok T, Ahn MJ, Han JY, Kang JH, Katakami N, Kim H, et al. CNS response to osimertinib in patients (pts) with T790M-positive advanced NSCLC: data from a randomized phase III trial (AURA3). J Clin Oncol. 2017;35(15 Suppl):9005.

17. Novello S, Barlesi F, Califano R, Cufer T, Ekman S, Levra MG, et al. Metastatic non-small-cell lung cancer: ESMO Clinical Practice Guidelines for diagnosis, treatment and follow-up. Ann Oncol. 2016;27(suppl 5):v1-27.

18. Douillard JY, Ostoros G, Cobo M, Ciuleanu T, McCormack R, Webster A, et al. First-line gefitinib in Caucasian EGFR mutation-positive NSCLC patients: a phase-IV, open-label, singlearm study. Br J Cancer. 2014;110:55-62.

19. Shigematsu H, Lin L, Takahashi T, Nomura M, Suzuki M, Wistuba II, et al. Clinical and biological features associated with epidermal growth factor receptor gene mutations in lung cancers. J Natl Cancer Inst. 2005;97:339-46.

20. Lee SH, Kim WS, Choi YD, Seo JW, Han JH, Kim MJ, et al. Analysis of mutations in epidermal growth factor receptor gene in Korean patients with non-small cell lung cancer: summary of a nationwide survey. J Pathol Transl Med. 2015;49: 481-8.

21. Goss G, Tsai CM, Shepherd FA, Ahn MJ, Bazhenova L, Crino $\mathrm{L}$, et al. CNS response to osimertinib in patients with T790Mpositive advanced NSCLC: pooled data from two phase II trials. Ann Oncol. 2018;29:687-93.

22. Rangachari D, Yamaguchi N, VanderLaan PA, Folch E, Mahadevan A, Floyd SR, et al. Brain metastases in patients with EGFR-mutated or ALK-rearranged non-small-cell lung cancers. Lung Cancer. 2015;88:108-11. 